\title{
UN CASO DE VARIACIÓN SINTÁCTICO-SEMÁNTICA DEL VERBO EN EL ESPAÑOL DE MAGALLANES: UNA APROXIMACIÓN SOCIOLINGÜÍSTICA*
}

MARGARITA MAKUC S.

\section{RESUMEN}

En este artículo se presenta la variación verbal desde un enfoque sociolingüístico, desde esta perspectiva de análisis las particularidades sociales, históricas y etnográficas del habla de una región se manifestarían en el uso de la lengua tanto en el nivel morfológico, sintáctico y semántico.

En el marco de la investigación acerca de la variación lingüística en Magallanes ${ }^{1}$ se presenta la variación sintáctico-semántica de los verbos considerados como variantes patrimoniales de la comunidad de habla magallánica: crecer (lo)---caer(lo)- pasar a caer (lo) .Desde un punto de vista teórico, estos verbos reflejarían procesos sintácticos de ergativización, es decir, aquellos procesos lingüísticos que se caracterizan por explicitar el agente de la acción expresada en la estructura gramatical del verbo. A su vez, en el plano semántico este proceso se manifiesta a través de la atribución de un significado particular a los verbos utilizados por los hablantes.

Entre las conclusiones principales, podemos señalar que el significado de estos verbos es reconocido por la totalidad de los hablantes encuestados, sin embargo, su uso está determinado por las variables de edad y escolaridad. Igualmente, podemos señalar que la variación sintáctico-semántica de los verbos en estudio se encontraría en un proceso inicial de cambio lingüístico (Labov, 1983) y que correspondería a aquellos usos lingüísticos que presentan menor concentración en ciertos grupos sociales.

PALABRAS CLAVES: Variación sintáctica- variación semántica- ergatividad-cambio lingüísticoverbos patrimoniales.

\footnotetext{
Universidad de Magallanes, casilla 113-D, Punta Arenas, Chile, margarita.makuc@umag.cl.

1 Este artículo presenta los aspectos específicos de la investigación sociolingüística iniciada en el año 1998 en el marco de la Tesis de Magíster en Lingüística (USACH) y desarrolla los objetivos alcanzados en el proyecto de investigación interno de la Universidad de Magallanes: "Estudio de la variación lingüística del español en la región de Magallanes", (Programa 025200/2006). Ayudante de Investigación: Sr. Miguel Bórquez.
} 


\section{THE SYNTACTIC-SEMANTIC VARIATION OF THE VERB IN SPANISH IN MAGALLANES: A SOCIOLINGUISTIC APPROACH.}

\section{ABSTRACT}

In this article verbal variation is presented from a sociolinguistic approach. From this perspective of analysis, social, historic and ethnographic peculiarities of speech of a region are manifested in the use of the language at a morphological, syntactic and semantic level.

In the context of the investigation about linguistic variation in Magallanes it is presented the syntactic-semantic variation of the verbs that are considered patrimonial variants of the Magellan community: crecer(lo) - pasar a caerr - caer(lo). From a theoretical point of view, these verbs would reflect syntactic processes of ergativity, that is to say, those linguistic processes that are characterized by making explicit the subject of the action mentioned in the grammatical structure of the verb. At the same time, at a semantic level this process is manifested by giving a particular meaning to the verbs used by the speakers.

Among main conclusions, we can say that the meanings of these verbs are recognized by all the people polled, however the use is determined by the variables of age and schooling. Likewise, we can also say that the syntactic-semantic variations of the verbs being studied are in an initial process of linguistic change (Labov, 1983) and that would correspond to those linguistic uses that present less concentration in certain social groups.

KEY WORDS: Syntactic variation - semantic variation - ergativity - linguistic change - patrimonial verbs.

\section{INTRODUCCIÓN}

La variación del verbo en el español de Magallanes presenta particularidades morfológicas, sintácticas y semánticas que nos permiten considerar los verbos como "variantes patrimoniales"; esto es como variantes propias de la región (Labov, 1983). Este proceso de variación experimentado por los verbos patrimoniales: Crecerlo (criarlo); Caerlo -pasar a caer (dejar caer) ha sido descrito por diversos autores como un tipo general de variación lingüística. Frente al uso transitivo de estos verbos, Kany (1970) plantea la noción de analogía para explicar el caso de transitivización del verbo "caer"; por su parte, Oroz (1966) considera el uso reflejo del verbo neutro (los niños se crecen) como producto del sustrato indígena.

En este estudio sociolingüístico los hablantes magallánicos fueron encuestados con la finalidad de que señalaran si consideraban adecuado el uso transitivo de verbos intransitivos inacusativos. Los verbos transitivos (dar, entregar, prestar) desde un punto de vista semántico, presentan un argumento interno que corresponde al rol temático inherente a la acción expresada en el verbo, en otras palabras, el argumento correspondería a la relación entre eventos e individuos (Schein,2002). Por su parte, los verbos intransitivos, que corresponden a los verbos de este estudio (sonreír, hablar, desaparecer, trabajar) no presentan argumento interno, a modo de ejemplo en la oración "Los niños sonreían" la acción del verbo no requiere de un complemento para completar su significado (Alarcos, 1994).

Los verbos intransitivos, a su vez, son clasificados como verbos inergativos y verbos inacusativos, la diferencia entre ambos tipos de verbos, radica en que los verbos inergativos denotan actividades o procesos que dependen de la voluntad de un agente (por ejemplo, Pedro trabajó, donde Pedro es un agente, causante del evento). Los verbos inacusativos, en cambio, se refieren a eventos instantáneos (eventos télicos) (Levin y Rappaport, 1995) y tienen sujetos no agentivos. En la oración El libro se cayó, el libro no es un agente, pues el evento de la caída le ha ocurrido al libro.

Al respecto, Mendikoetxea (1999) distingue dos clases semánticas de verbos inacusativos: verbos de cambio de estado o ubicación (romperse-abrir- 
se-hundirse-caerse-crecer) y verbos de existencia y aparición (aparecer-llegar-existir-ocurrir-venir-suceder). En los verbos de cambio de estado o ubicación, puede existir una causa externa que desencadene el proceso (se cayó) o bien una causa interna (el árbol creció), en donde el proceso se desarrolla por las propiedades inherentes del sujeto.

La transformación de un verbo intransitivo inacusativo a su utilización como verbo transitivo, se grafica en el ejemplo siguiente:

\section{Verbo Caer (Intransitivo inacusativo)}

\section{A. Los libros cayeron del estante SN1 Sujeto Verbo \\ Sujeto: Los libros (concuerda con el verbo: cayeron)}

En la oración (A) el verbo se considera un verbo inacusativo, de causa externa, cuyo sujeto no es agentivo, pues describe un evento instantáneo.

\section{B. Pedro cayó los libros}

SN1 Sujeto Verbo SN2 (Complemento Directo)

Sujeto: Pedro (concuerda con el verbo: cayó)

En la oración (B) el verbo puede clasificarse como un verbo transitivo cuyo sujeto es agente $y$ causa de la acción descrita por el verbo.

Como podemos observar en estos ejemplos la diferencia entre verbos intransitivos y transitivos radica, entre otros aspectos, en la noción de causalidad, este rasgo típico de las construcciones transitivas, lo podemos observar en el ejemplo B, en donde se ha explicitado la causa del evento mediante un sujeto agente que realiza la acción, a diferencia del ejemplo A, en que la acción explicitada por el verbo no presenta un sujeto agente, en este caso "Los libros" experimentan el proceso expresado en el verbo (sujeto paciente). Al mismo tiempo en este tipo de oraciones intransitivas la ausencia de causa se expresa mediante el pronombre "se". Al respecto, sostiene Demonte (2000) la transitivización de los verbos correspondería a un proceso de recategorización a partir de la explicitación de las causas de los eventos descritos. En el español, existiría un proceso léxico muy productivo que es el resultado de la causativización de los eventos y que da lugar a una forma transitiva con interpretación causativa o de evento externamente causado ("Quedé el libro encima de la mesa” "¡Cuidado no lo caigas!”).

Estudios recientes señalan que las formas verbales patrimoniales antes descritas, específcamente los verbos: crecerlo, caerlo, pasar a caer reflejarían procesos inherentes a la ergatividad de las lenguas (Mendikoetxea, 1999; Demonte, 2000, 2002a; Sabaj, 2002; Makuc, 2003) que implica, en términos generales, la capacidad de explicitar u ocultar el agente de la acción expresada en el verbo. Desde esta perspectiva se plantea que este proceso constituye un fenómeno complejo que se expresa en el paso de un elemento lingüístico a otra subclase de la categoría mayor a la que pertenece, debido a la intervención de un proceso léxico que tiene implicaciones sintácticas y manifestaciones morfológicas (Demonte, 2000). Un aspecto central de este nuevo enfoque lo constituye la noción de ergatividad, definida como un proceso mediante el cual los verbos de una lengua presentan grados de causalidad, es decir, gramaticalmente, los verbos requieren o restringen a cierto tipo de participantes o estructuras al expresar la causa de un proceso. Cabe mencionar al respecto, el interesante debate generado en torno a considerar la ergatividad como una característica de las lenguas, por lo que se podría incluso hablar de "lenguas ergativas" (Arias, 2000; Holmer, 2001)

El estudio de la variación sintáctico-semántica del verbo en el español de Magallanes se realiza en el marco de los estudios sociolingüísticos iniciados en la región y orientados describir la variación de la lengua en términos de factores sociales y lingüísticos (Makuc, 1999; 2003; 2007). A partir de lo anterior, este estudio se realiza con la finalidad de describir la variación provocada por variables sociales de edad, género y escolaridad, y de qué modo ello se expresa en el conocimiento y uso que los hablantes manifiestan en la encuesta sociolingüística aplicada en la ciudad de Punta Arenas, Puerto Natales y Porvenir. Por otra parte, interesa abordar los factores lingüísticos que posibilitan la presencia de estas variantes verbales en el sistema lingüístico del español y que se manifiestan en el nivel morfológico, sintáctico y semántico de la lengua. 


\section{ANTECEDENTES TEÓRICOS}

La variación lingüística de los verbos ha sido explicada desde diversas perspectivas, Kany (1970) propone analizar estos fenómenos a partir de los cambios semánticos ocurridos en una comunidad de habla, de este modo la transitivización de verbos intransitivos (caerlo-crecerlo-pasar a caer-) se explicaría como un hecho provocado por el cambio de significado atribuido al verbo definido como "analogía correlativa". La presencia de estos usos ha sido registrada por diversos estudios (Kany, 1970; Cano, 1981, Demonte, 2000) en el habla de regiones de España (Castilla, León, Andalucía, Mérida). Esta variante se habría conservado en el español de Chile, ya que investigaciones de orientación dialectológica han detectado su presencia en el habla de Chiloé, Cautín, Valdivia y Llanquihue (Oroz, 1966; Araya, 1973). En el contexto del estudio realizado sobre el español en la ciudad de Punta Arenas (Makuc, 1999) se observa que este uso aún persiste en la región de Magallanes y se explicaría a partir de las sucesivas corrientes migratorias provenientes de la región de Chiloé. Lo anterior permite señalar que las variantes en estudio constituyen variantes patrimoniales de la región por cuanto su uso se explica a partir de factores geográficos e históricos (Alvar, 1986) que la dialectología define como nivel "diatópico" y "diacrónico" y que permiten explicar los factores que intervienen en la evolución de las lenguas.

Los estudios dialectales de las lenguas constituyen la base para el desarrollo de la investigación sociolingüística, pues una vez identificadas estas variantes dialectales, se avanza hacia la explicación de los factores sociales que permiten comprender los procesos de cambio, difusión o restricción de las variantes lingüísticas en una comunidad de habla.

\section{LA VARIACIÓN SOCIOLINGÜÍSTICA}

La lengua entendida desde un enfoque social, desarrolla diferenciaciones internas que corresponden a los parámetros que caracterizan a los subgrupos que constituyen el sistema social. Las correlaciones variacionales entre lengua y sociedad han sido reconocidas desde siempre, pero los estudios cuantitativos del contexto social de la variación lingüística realizados en los últimos años han demostrado en forma sistemática y científica que los factores sociales actúan de manera probabilística en la variación (Pride, 1975; Labov, 1983; Silva, 1989; Moreno, 1999). Así el contexto físico en que ocurre la comunicación, las relaciones entre los participantes y tanto sus características sociales adscritas (género, escolaridad y edad) han mostrado reflejarse sistemáticamente en comportamientos lingüísticos diferenciados, esta covariación entre fenómenos lingüísticos y sociales es lo que caracteriza la variable sociolingüística, por ello diversos autores (Labov, 1983; Alvar, 1986; López, 1994; Spolsky, 2004) definen la variación sociolingüística como el reconocimiento de la existencia de diferentes realizaciones (variantes) de las unidades de cualquier sistema lingüístico en las cuales la variación se relaciona con factores sociales (edad, género y nivel sociocultural). La variable estable covaría, además, con el estilo, ya que en el estilo formal los hablantes usan un mayor número de formas asociadas con el habla de la clase alta y, en el estilo informal, ocurre lo contrario (Spolsky, 2004). Otra característica de las variables estables es que las reacciones subjetivas hacia ellas son también estables: los miembros de los diferentes grupos sociales estigmatizan las formas de menor prestigio y se autocorrigen en el habla espontánea en la dirección de la variante más prestigiosa.

Un concepto central para la comprender la variación sociolingüística es la noción de Comunidad de habla, este concepto alude a la distinción entre lengua y habla, señalando que la comunidad de habla no sólo es un conjunto de hablantes que comparten efectivamente, al menos una lengua, sino que, además, comparten un conjunto de normas y valores de naturaleza sociolingüística, es decir, actitudes lingüísticas, reglas de uso y un criterio compartido a la hora de evaluar socialmente los hechos lingüísticos, por tanto, los hispanohablantes pertenecerían a una misma comunidad idiomática, pero no a una misma comunidad de habla. La teoría sociolingüística plantea que el proceso de cambio lingüístico experimentado en una comunidad de habla comienza cuando una variante se generaliza en un sub-grupo de una comunidad y adquiere una dirección y significación social, este cambio, sin embargo forma parte de las opciones que permite el propio sistema lingüístico. Este tipo de cambio o variación, se produciría en dos direcciones, "desde abajo" (Labov, 1983), pues es impulsado por determinados grupos generacionales o de baja escolaridad 
que transgreden la normativa de su lengua, o bien ser un cambio desde arriba (o cambio consciente) que se caracteriza porque los hablantes están conscientes de que se trata de un rasgo lingüístico estigmatizado, por tanto las instituciones educativas evitan la expansión de variantes lingüísticas consideradas como variantes que no pertenecen a la lengua estándar.

La investigación sociolingüística reciente (Hudson, 1981; López Morales, 1994; Moreno, 1999; Lavandera, 1992; Almeida, 2003) plantea que la variación experimentada por las lenguas, así como la presencia de una o más variantes lingüísticas en una comunidad de habla responden a la combinación de factores lingüísticos y sociales. De este modo, la variación entre un uso transitivo o intransitivo del verbo ha sido estudiado a partir de la distinción teórica establecida entre las nociones de transitividad e intransitividad de los verbos del español (Cano, 1981; Hernández, 1984).

La transitividad es definida como la posibilidad o imposibilidad de que el verbo admita objeto, ya que habría verbos que no pueden prescindir de su objeto (obtener, difundir, reconocer) y por otra parte, verbos que se caracterizan por ser intransitivos (crecer, ir, caer). Desde una perspectiva funcional, esta clasificación de los verbos no respondería a rasgos especiales del contenido de la raíz verbal, pues en general la presencia o ausencia de objeto directo dependería de la intención comunicativa, lo que permitiría describir la transitividad como un continuo, que en el uso de la lengua se manifestaría en "grados de transitividad" (Alarcos, 1994; Di Tullio, 1999)

Desde esta perspectiva, en el estudio actual de la variación en la lengua se ha propuesto la noción de "ergatividad" para explicar usos dialectales que reflejan un rasgo continuo más o menos ergativo que caracterizaría a todas las lenguas. Así entendida, la ergatividad es un parámetro más de la cognición humana que se activa o se inhibe no dicotómicamente sino gradualmente como parte de un continuum. En este sentido, la ergatividad de las lenguas ha de definirse dentro de una teoría más general concerniente a las causas, pues lo ergativo no implica la ausencia de una causa sino más bien constituye una forma más implícita, atenuada o modalizada de presentar la causa de un proceso o de un estado. La ergatividad se entiende, de esta forma, como un mecanismo de la cognición a través del cual se omiten o se debilitan las causas de los hechos y las cosas del mundo (Sabaj, 2002). Las construcciones ergativas, por tanto, (Mendikoetxea, 1999) son aquellas construcciones cuyo verbo requiere sólo un participante, el cual, además, no es el agente de la acción (Ejemplo: "El árbol creció"). Como se observa en este ejemplo, que corresponde a una construcción típicamente ergativa, el sujeto es paciente de la acción, pues no participa activamente en dicho proceso, del mismo modo ocurre en las construcciones pasivas con se (Ejemplo: "El vaso se cayó"), con las que se ha establecido un paralelo, pues en ambos casos se grafica la ergatividad en cuanto a que la causa del proceso se ha omitido y permanece en forma implícita. En el caso de los verbos de nuestro estudio: Pedro lo cayo (el vaso) y "Yo los crecí a mis hijos con mucho sacrificio"; se observa que las construcciones ergativas han sufrido un proceso de agentivización (en términos de la gramática tradicional se han transitivizado), es decir se ha explicitado el agente de la acción y a su vez la acción recae en un objeto directo. Esta variación sintáctica (oración intransitiva se transforma en transitiva) y morfológica (adición del pronombre acusativo "lo"), implica una variación semántica en tanto la explicitación del agente de la acción nos remite al significado del verbo crecer en el sentido de "educar", "criar"; y en el caso del verbo caer al sentido de "dejar caer", "lanzar involuntariamente.

\section{METODOLOGÍA}

Los procedimientos utilizados en nuestro estudio corresponden a las metodologías propias de la investigación sociolingüística (Silva, 1989; Moreno, 1990; López, 1994; Almeyda, 2003) de este modo se estableció una muestra no probabilística de hablantes estratificados de acuerdo a la variable edad, género y escolaridad. Por otra parte, las variables lingüísticas verbales identificadas, previamente, en entrevistas y revisión bibliográfica (Makuc, 1998; Kany, 1970; Oroz, 1966; Demonte, 2000; Makuc, 2003) se someten a una encuesta sociolingüística en 144 hablantes, correspondientes a 72 personas en Punta Arenas, 36 personas en Puerto Natales y 36 en Porvenir. Los resultados obtenidos en las encuestas fueron analizados de acuerdo a la frecuencia de respuestas relacionadas con el conocimiento y el 
uso de las variables consultadas. Los resultados han sido clasificados en una tabla de acuerdo a género, edad y escolaridad de los encuestados, con el fin de identificar la relación entre las variantes verbales en estudio y las variables sociales.

\section{OBJETIVOS DEL ESTUDIO:}

1.- Determinar el conocimiento y uso de las variantes patrimoniales: Crecerlo (criarlo); Caerlo (dejar caer)-pasar a caer (dejar caer).

2- Establecer si el conocimiento y uso están determinadas por variables sociales, esto es: escolaridad, edad o género.

3- Identificar algunas de las principales propuestas para explicar los procesos lingüísticos que intervienen en la variación socio-lingüística.

\section{MUESTRA DEL ESTUDIO}

La muestra del estudio está constituida por 144 hablantes de la región de Magallanes, a quienes se les aplicó la encuesta sociolingüística en las ciudades principales de la región: Punta Arenas (72), Puerto Natales (36) y Porvenir (36). Se trata de una muestra no probabilística intencionada y por lo tanto, se seleccionó un número de hablantes estratificados según género, edad y escolaridad. De este modo los hablantes se distribuyeron del siguiente modo:

\section{INSTRUMENTO}

El estudio de las variables sociolingüísticas de la región se realizó aplicando una encuesta sociolingüística compuesta por oraciones que integraban los verbos en estudio, frente a las cuales se les consultaba a los sujetos acerca del conocimiento de la expresión así como el uso de ellas. La encuesta sociolingüística estuvo conformada por 14 oraciones, entre las cuales 8 de ellas corresponden a oraciones experimentales y 6 a oraciones no experimentales, (Ver Anexo) las oraciones no fueron presentadas en el mismo orden a todas las personas, ya que su distribución fue aleatoria. Los encuestados debían responder en forma afirmativa o negativa tanto para el conocimiento como para su uso. Para corroborar las respuestas afirmativas se inducía a los entrevistados a señalar el significado de la expresión, en el caso de las expresiones conocidas y usadas. Entre las dificultades de este instrumento se presenta el hecho de que las personas tienden a responder aquello que perciben como correcto, es decir de acuerdo a criterios normativos, este problema puede disminuir integrando, a futuro, imágenes y escenarios que activen el uso de estas expresiones en contextos simulados.

A modo de ejemplo, se presenta un aspecto de la encuesta sociolingüística aplicada. A través de este instrumento, se le pide a los encuestados que indique si conoce, usa (o ha usado) y el significado de las siguientes expresiones:

\begin{tabular}{|c|c|c|c|}
\hline MENOS DE 12 AÑOS DE ESCOLARIDAD (48) & MASCULINO & FEMENINO & Total \\
\hline $15-25$ & 8 & 8 & 16 \\
\hline $25-50$ & 8 & 8 & 16 \\
\hline $50-65$ & 8 & 8 & 16 \\
\hline Total & 24 & 24 & 48 \\
\hline 15-25 & & & 16 \\
\hline $25-50$ & 8 & 8 & 16 \\
\hline $50-65$ & 8 & 8 & 16 \\
\hline Total & 8 & 88 & 48 \\
\hline 12 NNOS DE ESCOLARIDAD (48) & 24 & 24 & 16 \\
\hline MÁS DE 12 AÑOS ESCOLARIDAD (48) & & & 16 \\
\hline $25-50$ & 8 & 8 & 16 \\
\hline $50-65$ & 8 & 8 & 48 \\
\hline Total & 8 & 8 & 144 \\
\hline
\end{tabular}




\begin{tabular}{|l|l|l|l|}
\hline \multicolumn{1}{|c|}{ EXPRESIÓN } & CONOCIMIENTO & \multicolumn{1}{|c|}{ USO } & \multicolumn{1}{|c|}{ SIGNIFICADO } \\
\hline Mis hijos se crecieron solos & & & $\begin{array}{l}\text { Mis hijos se criaron solos, se desarrollaron } \\
\text { solos, no tuvieron apoyo paterno }\end{array}$ \\
\hline Yo lo crecí con mucho sacrificio & & & Los eduqué, los crié con mucho sacrificio \\
\hline Lo cayó su hermano & & & Lo botó, lo empujó \\
\hline El chico pasó a caer sus cuadernos & & & Tiró, botó accidentalmente \\
\hline
\end{tabular}

\section{PRESENTACIÓN Y DISCUSIÓN DE LOS RESULTADOS}

Los resultados de este estudio permitieron identificar el conocimiento y uso de las variantes verbales, posteriormente estos resultados se organizaron con la finalidad de identificar si el conocimiento y el uso de las variantes se relaciona con el género, la edad y la escolaridad de los encuestados. Como observamos en el cuadro anterior, se pudo registrar el significado atribuido por los encuestados a los verbos en el contexto de las oraciones.

Es importante señalar que los resultados obtenidos no arrojaron diferencias relacionadas con las opiniones que tienen las personas sobre las oraciones individuales y tipos de verbos, pues los significados atribuidos a las expresiones fueron reconocidos y compartidos, tanto en el contexto oracional como individualmente. Respecto de los verbos del estudio: caerlo/ pasar a caerlo/crecerlo, podemos observar que en la tabla anterior se registran otros usos de estos verbos y por tanto potros significados, por ejemplo el verbo crecer se presenta en la oración refleja "Yo me crecí en Puerto Natales; igualmente el verbo pasar a caer se observa en su uso pseudoreflejo: me pasé a caer en la escarcha. En otros casos se conserva el verbo en infinitivo "Pasar a" como en las oraciones "Pasé a traer el florero", "Estos lomos se pasan a traer" (se pasan a llevar, se tiran accidentalmente).

\section{CONOCIMIENTO Y USO DE LAS}

\section{VARIANTES VERBALES EN RELACIÓN} AL GÉNERO, EDAD Y ESCOLARIDAD DE LOS PARTICIPANTES

Los resultados de la aplicación de la encuesta en las ciudades de Punta Arenas, Puerto Natales y Porvenir, permitió observar que en la relación entre conocimiento y uso de las variantes verbales un alto porcentaje de participantes afirma conocer las variantes consultadas y un menor porcentaje reconoce usar estas variantes, este resultado no varía significativamente entre las ciudades del estudio. Entre los 144 entrevistados se presentan 92, $60 \%$ de respuestas afirmativas sobre el conocimiento de las variantes verbales consultadas, este conocimiento evidenciado en las respuestas de los participantes contrasta con el 48,0 \% de respuestas afirmativas respecto del uso de estas mismas variantes.

\section{CONOCIMIENTO DE LAS VARIABLES VERBALES}

Respecto del conocimiento que los hablantes manifiestan de las variantes verbales no se observan significativas diferencias atribuibles a la edad, a la escolaridad o al género de los participantes del estudio. Como podemos observar en las figuras siguientes la distribución de los porcentajes de respuestas afirmativas respecto del conocimiento de los participantes sobre las variantes consultadas refleja una mínima diferencia atribuible al género, edad y escolaridad de los participantes del estudio.

El análisis de los resultados obtenidos en la variable género nos indica que las expresiones y sus respectivos significados son ampliamente conocidos por la comunidad de habla, lo que se expresa en el hecho de que el 96\% de los hablantes de género femenino conoce las expresiones dadas, así como los hablantes de género masculino que señalan conocer las variables en un $90 \%$. Como podemos observar el grado de conocimiento de las variables es mayor en mujeres que en hombres, aún cuando, está diferencia no es significativa (6\%). En consecuencia, podemos inferir que la variable género no constituye un factor que incide significativamente en el conocimiento de las variantes lingüísticas en estudio.

Por su parte, en la variable edad, podemos observar resultados muy similares respecto del género, pues los tres grupos en que se subdividió la muestra conocen en un porcentaje similar las expresiones verbales consultadas. Los participantes más jóvenes (15-25 años) respondieron afirmativa- 
mente en un 92\%; los participantes adultos (25-50 años) declaran conocer las expresiones con un $98 \%$ de respuestas afirmativas, $y$, finalmente, los participantes mayores de 50 años sostienen un $96 \%$ de respuestas afirmativas

Con respecto a la escolaridad la distribución de los resultados se realizó agrupando en tres niveles posibles de escolaridad: i) doce años de escolaridad (enseñanza media completa) ii) menos de doce años (básica, media incompleta, etc.) y iii) Más de doce años de escolaridad (Educación superior).En relación a la variable nivel de escolaridad se mantiene la tendencia observada en la variable edad y género, en cuanto los tres grupos independientemente de su escolaridad conocen las variantes en porcentajes similares

\section{USO DE LAS VARIANTES VERBALES}

Sin embargo, estos resultados obtenidos para describir el conocimiento que los hablantes poseen de las variantes, presenta diferencias significativas en la pregunta referida al uso de las expresiones consultadas. Pues, el análisis de cada uno de los grupos en que clasificamos a los hablantes, sí nos permitió identificar dos variables sociales que inciden en la mayor o menor frecuencia de respuestas de los participantes. Una de estas variables es la escolaridad que se manifiesta como un factor que incide en el uso de las variantes, ya que el mayor porcentaje de respuestas afirmativas se ubica entre los participantes de escolaridad baja (menos de 12 años) este grupo sostiene en un $70 \%$ respuestas

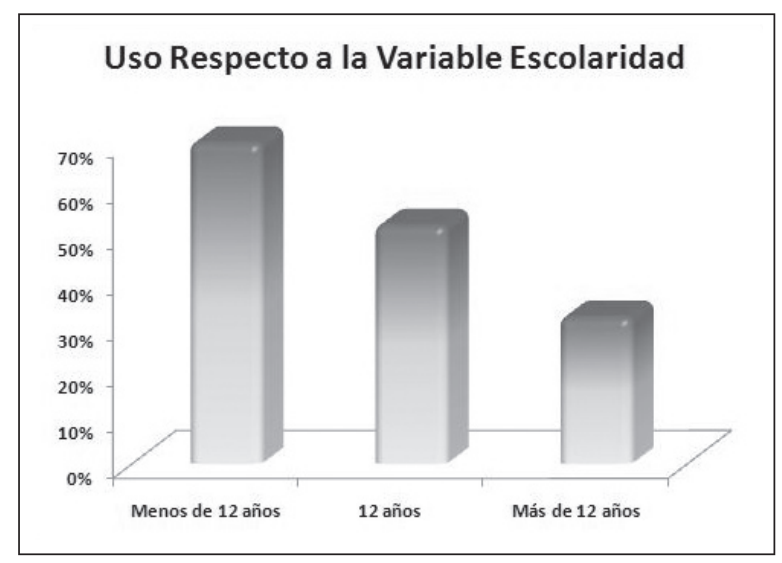

Fig. № 1. Relación entre el uso de las variantes y la variable escolaridad. afirmativas en relación al uso de las variantes. Al mismo tiempo, el grupo con escolaridad alta (más de 12 años) presenta el menor porcentaje de respuestas afirmativas (32\%) respecto al uso (Fig. № 1 ).

Igualmente, en el factor referido a la edad de los encuestados, las diferencias son similares, pues el grupo generacional que oscila entre los 15 y 25 años manifiesta en un $58 \%$ usar las variantes encuestadas, a diferencia del grupo entre 25-50 años en que sólo un 28 \% señala usar las variantes verbales. Esta diferencia que existe entre ambos grupos diferenciados por edad y escolaridad nos permite señalar que la escolaridad y la edad son factores asociados al menor o mayor uso de las variantes verbales (Ver Fig. №2 )

La mayor frecuencia en el uso de las expresiones reconocido por jóvenes y adultos mayores, nos muestra un hallazgo en términos de las diferencias que han sido registradas por diversos estudios respecto de la edad como factor de diferenciación. Al contrario, en estos resultados observamos que estas variantes no son restringidas, tanto por jóvenes que adhieren al uso de variantes estigmatizadas por el grupo de escolaridad alta y de entre 25 y 50 años. Los hablantes de mayor edad, conservan en el uso variantes locales, como expresión de identidad local.

\section{DISCUSIÓN DE RESULTADOS}

Como se observa en los resultados, los participantes reconocen mayoritariamente conocer las variantes verbales, sin embargo su uso no es

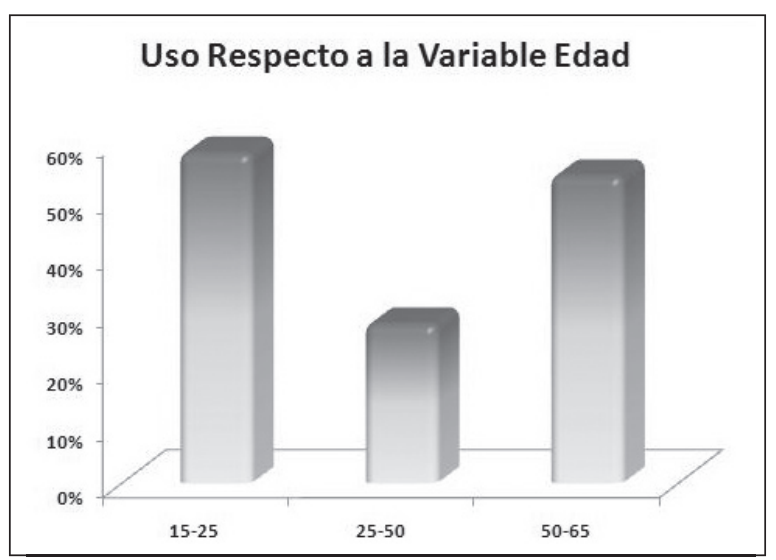

Fig. № 2. Relación entre el uso de las variantes y la edad. 
compartido. En la comunidad de habla magallánica la diferencia evidenciada en el mayor conocimiento de las variantes y el menor uso de ellas estaría relacionado con las variables de edad y escolaridad. Con respecto al primer factor, esto es la variable edad, se ha planteado en diversas investigaciones (Silva, 1989; Moreno, 1998; Almeida, 2003) como uno de los factores más determinantes de la variación, pues la edad no sólo sería un factor cronológico, sino que conllevaría una serie de implicaciones sociales, psicológicas y económicas que se expresan en cambios de conducta social y lingüística. Este grupo etáreo, se define como un grupo que se caracteriza por un mayor volumen de expresiones estigmatizadas, lo que los convierte en participantes activos del cambio lingüístico, al mismo tiempo las expresiones socialmente valoradas como marcadoras de prestigio, no constituyen un factor relevante para quienes en su gran mayoría no se han incorporado al mundo laboral y/o profesional. Igualmente, se observa una mayor frecuencia en el uso de las expresiones en hablantes de mayor edad, este hecho puede atribuirse a que estas variantes locales, se conservan como expresiones dialectales que forman parte de la identidad, regional y son incorporadas a la región en el inicio de la población inmigrante de Chiloé. Los hablantes mayores, al mismo tiempo están menos expuestos a las influencias del intercambio sociocultural y económico que promueve en el caso de los hablantes adultos, el reemplazo de variantes locales por aquellas menos locales. Dos aspectos distintos explicarían el uso de las variantes entre jóvenes y adultos mayores, por una parte, los jóvenes no restringen el uso de aquellas variantes estigmatizadas, ni adhieren a valorar el uso de expresiones marcadoras de prestigio. Por otra parte, entre los hablantes mayores, pareciera ser un indicador de conservadurismo, el mantener el uso de las variantes, como expresión de identidad local. Inversamente, el grupo generacional que presenta menor porcentaje de respuestas afirmativas respecto al uso de variantes verbales está constituido por participantes que se encuentran integrados a la sociedad a través del trabajo, profesión o estudios superiores. El desarrollo de relaciones interpersonales que implican cambios en la conducta lingüística de los hablantes, la conciencia lingüística de las variantes de prestigio y de las variantes estigmatizadas conlleva desechar variantes patrimoniales y asumir expresiones estandarizadas. Pareciera ser que las variantes verbales de nuestro estudio son percibidas como variantes locales que no responden a la norma estándar y, en consecuencia, su uso debe restringirse en situaciones de habla formal. El estilo de la encuesta, como sabemos, es reconocido por los hablantes como un estilo cuidadoso en que los sujetos prestan mayor atención a lo que dicen y de manera consciente evitan usar construcciones coloquiales. Es interesante destacar el alto porcentaje de uso (54\%) de las variantes verbales en el grupo de mayor edad, ello nos ratifica su carácter patrimonial, pues estas expresiones forman parte del habla de la comunidad magallánica y su presencia se explica por factores geográficos e históricos que explican su uso (Oroz, 1966; Kany, 1970; Araya, 1973)

El análisis de la variable escolaridad se inscribe en el marco de la variación sociolectal, desde esta perspectiva, el impacto de factores socioeconómicos en la lengua se asocia al uso de variantes de prestigio o estigmatizadas. En este sentido, la mayor frecuencia de estas variantes en el grupo de menor escolaridad (70\%) nos indica que este resultado, coincide con diversas investigaciones que sostienen que el habla de los grupos de menor escolaridad presenta variantes lingüísticas y usos dialectales que configuran una serie de rasgos fonéticos, fonológicos, gramaticales y lexicológicos asociados a un grupo social definido (Guy, 1992;Lavandera, 1992; Halliday, 1994). Por otra parte, los hablantes con mayor escolaridad sólo alcanzan un 32\% de respuestas afirmativas de uso de las variantes. Por consiguiente, existiría un control de su expansión a medida que aumentan los años de escolaridad, este proceso de control se caracteriza por ser un proceso consciente que impide que las variantes de menor prestigio se socialicen (López, 1994; Moreno, 1999).

Desde un punto de vista lingüístico podemos concluir que el uso de estas expresiones se explica a partir de considerar esta variación sociolingüística como un proceso de causitivización que experimentan las construcciones ergativas, es decir construcciones cuyo único participante no es el agente de la acción (Ejemplo: "El árbol creció" "El niño se cayó"). Estas oraciones, están compuestas por verbos de naturaleza inacusativa (sin agente explícito), sin embargo en el caso particular de la región de Magallanes las construcciones ergativas han sufrido un proceso de agentivización (en términos de la gramática tradicional 
se han transitivizado), es decir se ha explicitado el agente de la acción y a su vez la acción recae en un objeto directo: "No lo caigas". Por tanto en el uso de estas variantes, la variación sociolingüística se manifiesta en tres niveles de la lengua: nivel morfológico (adición del pronombre acusativo "lo"); nivel sintáctico (oración intransitiva con un uso transitivo y nivel semántica, pues la explicitación del agente de la acción nos remite al significado del verbo crecer en el sentido de "educar", "criar"; y en el caso del verbo caer al sentido de "dejar caer", "lanzar involuntariamente". Este proceso de causativización, que implica el paso de un elemento verbal a otra subcategoría se manifiesta en el uso de los verbos: crecer (lo); pasar a caer (lo); caer (lo).

\section{CONCLUSIONES}

A modo de conclusión, podemos señalar que a nivel de las expresiones verbales analizadas en este estudio: crecer (lo) (criarlo)-caer (lo) (dejar caer)--pasar a caer (lo) se observa un claro proceso de cambio lingüístico consolidado diatópicamente, pues las variantes verbales corresponden a un uso dialectal del español que han sido registradas por diversos autores (Oroz, 1966; Kany, 1970; Araya, 1973; Makuc, 1999; Demonte, 2000) como variantes verbales registradas en algunas regiones de España y en la zona sur de Chile. Lo anterior se confirma en el hecho de que un porcentaje importante de hablantes $(92,6 \%)$ conoce las variantes lingüísticas independientemente de factores sociales adscritos.

No obstante lo anterior, en la comunidad de habla magallánica el análisis de los factores sociales que intervienen en la presencia de las variantes sociolingüísticas nos indica que estamos frente a variantes del español en proceso de cambio lo que se manifiesta en una tendencia a la disminución observada en el uso. Sin embargo, dado el alto porcentaje observado en el conocimiento de las variables verbales podemos considerar que ésta sería una etapa inicial de un proceso de transformación en marcha; dicho cambio estaría focalizado en los adultos de escolaridad alta que fluctúan entre los 25 y 45 años.

Como se ha señalado anteriormente, los factores sociales que inciden mayoritariamente en este cambio manifestado en el uso se relacionan fundamentalmente con la variable escolaridad y la variable edad. Considerando que el cambio lingüístico observado en el uso de estas variantes verbales en Magallanes se relaciona fundamentalmente con la escolaridad de los hablantes; es que podemos caracterizar este proceso como un cambio "desde arriba" Lavob (1983), por cuanto son las instituciones educativas quiénes se encargan de evitar la expansión de variantes lingüísticas consideradas como no estándares o bien procesadas por el sistema educativo como variantes que no pertenecen a la lengua estándar (variantes correctas en el sentido gramatical normativo). Lo anterior, se refleja en el hecho que el grupo de menor escolaridad presenta un $70 \%$ de uso de las variantes encuestadas.

Por otra parte, un factor importante que estaría incidiendo en este cambio es lo que en sociolingüística se define como <actitud lingüística> (Silva, 1989; Moreno, 1998; Lavob, 1983, Almeida, 2003). La actitud lingüística se vincula con el hecho de que las variantes verbales consultadas se perciben como "incorrectas" o "poco apropiadas" por lo que los participantes se auto corrigen al momento de su uso. La actitud de los hablantes, por lo tanto, es de restricción hacia el uso de estas variantes, lo que constituye un factor relevante en la posibilidad de que éstas se expandan especialmente en los grupos de mayor escolaridad, lo que nos permite inferir igualmente que el uso de estas variantes estaría socialmente estigmatizado, en tanto sólo el 32 \% de ellos reconoce usar dichas expresiones. Con respecto a la edad, el porcentaje menor de hablantes que señala usar estas variantes, se encuentra en el grupo entre los 25 y 45 años, en este grupo sólo un $28 \%$ reconoce usar las expresiones consultadas, lo anterior nos permite proponer la idea de "mercado lingüístico" (Guy, 1992) para explicar el control social al que este grupo etareo se encuentra sometido debido a su incorporación a la actividad laboral y profesional que impone el uso de la lengua estándar y restringe tanto el uso de variantes estigmatizadas como patrimoniales. Este hecho se puede reforzar mediante el resultado que observamos en los jóvenes, quienes en un 58\% reconoce usar estas variantes, este alto porcentaje de uso entre personas que aún no se incorporan a la actividad laboral o profesional, coincide con las observaciones a las que llega Silva (1989) en cuanto a que, en el marco de los estudios sociolingüísticos, 
la variable edad permite observar que la juventud tiende a utilizar con mayor frecuencia variantes no estándarizadas, e incluso estigmatizadas.

Finalmente, desde una perspectiva lingüística, este fenómeno de variación verbal presente en el español de Magallanes puede interpretarse como un hecho que expresa un fenómeno de variación paramétrica, la noción de parámetro (Chomsky, 1999) nos remite a la idea de que las lenguas obedecen a principios comunes de naturaleza gramatical (Gramática universal) que interactúan con parámetros específicos de las lenguas particulares, por lo que la variación dialectal sería el resultado de la interacción de un conjunto finito de parámetros con los principios, reglas y mecanismos de la gramática universal. (Demonte, 2002ª ${ }^{\mathrm{a}}$ )

Como podemos observar la variación verbal en la región de Magallanes presenta las características propias de la variación sociolingüística, pues estos procesos de cambio se originan tanto por variables sociales (edad, género, escolaridad), como por variables lingüísticas, ya que los mismos sistemas lingüísticos, reúnen características estructurales universales que permiten a los hablantes provocar cambios en los distintos niveles de las lenguas con la finalidad de satisfacer necesidades comunicativas.

\section{ANEXO}

Consulta Sociolingüística

En las siguientes expresiones, por favor indique si conoce usa (o ha usado) las siguientes expresiones:

\begin{tabular}{|c|c|c|c|}
\hline Expresión & La conoce & La usa & Significado \\
\hline 1. Mis hijos se crecieron solos & & & \\
\hline 2. Lo cayó su hermano & & & \\
\hline 3. Me crecí en Puerto Natales. & & & \\
\hline 4. Oye casi me caíste la puerta del auto & & & \\
\hline 5. Yo lo crecí con mucho sacrificio & & & \\
\hline $\begin{array}{l}\text { 6. Estos lomos de archivadores se pasan a traer } \\
\text { fácilmente porque el papel es muy malo }\end{array}$ & & & \\
\hline 7. Siente Sra Margarita & & & \\
\hline $\begin{array}{l}\text { 8. Una señora llamó privada porque le habían } \\
\text { vendido una cassata derretida }\end{array}$ & & & \\
\hline 9. Me pasé a caer con la escarcha. & & & \\
\hline 10. Yo no lo caí el cuchillo & & & \\
\hline $\begin{array}{l}\text { 11. Seguramente alguien debe haberlos caído (los } \\
\text { documentos) accidentalmente (locutor de radio) }\end{array}$ & & & \\
\hline 12. Alguien queda en las Naciones (pregunta chofer de colectivo) & & & \\
\hline 13. Pasé a traer el florero & & & \\
\hline 14. El chico pasó a caer sus cuadernos & & & \\
\hline
\end{tabular}




\section{BIBLIOGRAFÍA}

ALARCOS, E. 1994. Gramática de la Lengua Española, Madrid: Espasa Calpe.

ALMEIDA, M. 2003. Sociolingüística. España: Universidad La Laguna.

ALVAR, M. 1986. Hombre, etnia y Estado, Madrid: Gredos

ARAYA, G. 1973. Atlas Lingüístico/ Etnográfico del Sur de Chile (ALESUCH) Preliminares y Cuestionario. Valdivia: № 1 Anejos de Estudios Filológicos: Universidad Austral de Chile.

ARIAS, A. 2000. "Una definición pluridimensional del sujeto lingüístico" en http://classes.colgate.edu/enrique

CANO, R. 1981 Estructuras sintácticas transitivas en el español actual, Madrid, Gredos.

CHOMSKY, N. 1999. El programa minimalista, Madrid: Alianza.

DEMONTE, V. 2000. Gramática, variación y norma: una tipología. En: Estudios Hispánicos: Asociación Coreana de Hispanistas, 12.

DEMONTE, V. 2002a. Microvariación sintáctica en español. Rasgos, categorías y virus, Actas del XIV Congreso de la Sociedad Chilena de Lingüística (SOCHIL).

DEMONTE, V. 2002b. Sintaxis del español. Seminario dictado en el Programa de Doctorado de la Universidad Católica de Valparaíso.

DI TUlliO, A. 1999. Manual de gramática del español, Buenos Aires: Paidós.

GUY, G. 1992. Mercado y clase social. En Panorama de la Lingüística Moderna. Universidad de Cambridge, pp. 57-86.

HALLIDAY, M. 1994. El lenguaje como semiótica social, México: Fondo de Cultura Económica.

HERNÁNDEZ, C. 1984. Gramática funcional del español, Gredos, Madrid.

HOLMER, A. 2001. "The ergativity parameter". Working Papers (48) 101-113.

HUDSON, R. 1981. La Sociolingüística, Barcelona: Anagrama.

KANY, CH. 1970. Sintaxis Hispanoamericana, Madrid: Gredos.

LABOV, W. 1983. Los modelos sociolingüísticos. Madrid: Cátedra.

LAVANDERA, B. 1992. El estudio del lenguaje en su contexto socio-cultural. En Panorama de la Lingüística Moderna. Universidad de Cambridge, pp. 15-29.
LEVIN, B. y M. RAPPAPORT HOVAV, 1995. Unnaccusativity: At the syntax-lexical semantics interface. Cambridge, MA: MIT.

LÓPEZ, H. 1994. Métodos de investigación lingüística, Salamanca: Colegio de España.

MAKUC, M. 1998. El perfil lingüístico del español de Punta Arenas. Tesis para optar al grado de Magíster Artium en Lingüística Hispánica USACH.

MAKUC, M. 1999. El español de Punta Arenas: un enfoque sociolingüístico", en Revista Austro Universitaria, ${ }^{\circ}$ 11/1999, Universidad de Magallanes.

MAKUC, M. 2003. La transitivización del verbo "caer" una aproximación sociolingüística al fenómeno de la variación sintáctica en la región de Magallanes" Revista Sophia Austral, Universidad de Magallanes, 2003, 8, 28-33.

MAKUC, M. 2007. La variación sintáctico-semántica del verbo en el español de Magallanes: una aproximación sociolingüística. Ponencia en congreso SOCHIL, 2007. Actas Congreso.

MENDIKOETXEA, A. 1999. Construcciones con sé: Medias, pasivas e impersonales. En: Bosque \& V. Demonte (Eds.) Gramática descriptiva de la lengua española. Madrid: Espasa Calpe pp.1635-1722.

MORENO, F. 1990. Metodología sociolingüística, Madrid: Gredos.

MORENO, F. 1999. Principios de sociolingüística y sociología del lenguaje. Barcelona: Ariel.

OROZ R. 1966. La Lengua Castellana en Chile, Santiago: Universidad de Chile.

PRIDE, J. 1975. Sociolingüística en Lyons, J (comp.), Nuevos Horizontes de la Lingüística, Madrid: Alianza, pp. 145-173.

SABAJ, O. 2002. Estudio Crítico Comparativo: La ergatividad, posibles aplicaciones para el análisis textual, Revista Signos, 35 (51-52), 231-241.

SCHEIN, B. 2002. "Events and the semantic content of gramamatical relations" En Preyer, G. \& Peter, G. (Eds.), Logical form and language" Oxford University Press, New York.

SILVA C. 1989. Sociolingüística. Teoría y análisis, España: Alhambra.

SPOLSKY, B. 2004. Sociolinguístics, Oxford: University Press. 